\title{
Congenital heart diseases in premature newborns.
}

\footnotetext{
1. MBBS

Post Graduate Trainee

Department Pediatric Medicine, Children's Hospital \& ICH, Multan

2. MBBS

House Officer

Department of Pediatric Medicine, Holy Family Hospital, Rawalpind

3. MBBS, FCPS (Paediatric Medicine)

Associate Professor Paediatric

Medicine

Children's Hospital \& ICH, Multan.

4. MBBS,

FCPS (Paediatric Cardiology)

Associate Professor Paediatric

Cardiology

Children's Hospital \& ICH, Multan.
}

Correspondence Address:

Dr. Asim Khurshid

Department of Paediatric Medicine

The Children's Hospital \& ICH, Multan. asimkhurshiddr@gmail.com

Article received on:

03/10/2020

Accepted for publication:

$19 / 12 / 2020$
Sana Ilyas ${ }^{1}$, Sana Waqar ${ }^{2}$, Asim Khurshid ${ }^{3}$, Muhammad Sohail Arshad ${ }^{4}$

ABSTRACT... Objective: To determine the frequency of congenital heart diseases (CHD) in newborns admitted with prematurity. Study Design: Descriptive Cross Sectional study. Setting: Department of Pediatric Neonatology Children's Hospital \& The Institute of Child Health, Multan. Period: August 2019 to January 2020. Material \& Methods: A total of 155 preterm infants $\leq 36$ weeks gestation were included. In preterm newborns of either gender, echocardiography was done by hospital Pediatric Cardiologist. Patient's name, age, gestational age, weight, sex, date, serial number, registration number and echocardiographic results were entered in predesigned performa. The outcome variable was frequency of congenital heart disease in preterm newborns. Results: Congenital heart disease was detected in $34.8 \%(n=54)$ preterm infants. Nine percent $(n=14)$ were $<1.5 \mathrm{~kg}, 45.2 \%(n=70)$ between $1.5-2.0 \mathrm{~kg}$ and $45.8 \%(n=71)$ were $>2.0 \mathrm{~kg}$ in weight. Most frequent lesion was Ventricular Septal Defect (VSD) in 19 (35\%) infants followed by patent ductus arteriosus (PDA) in $15(28 \%)$ infants. Atrial Septal Defect (ASD) was seen in $6(11 \%)$ preterm infants. Frequency of CHD was significantly higher ( $p$-value $<0.001)$ in babies delivered at $\leq 32$ weeks and those infants with with birth weight $<1.5 \mathrm{~kg}$. Conclusion: The study highlights the association of congenital heart diseases in premature and low birth weight neonates. So, every preterm and low birth weight neonate must undergo echocardiography to screen for $\mathrm{CHD}$ so that earlier diagnosis may be made for earlier intervention.

Key words: $\quad$ Congenital Heart Disease, Frequency, Neonates, Preterm.

Article Citation: llyas S, Waqar S, Khurshid A, Arshad MS. Congenital heart diseases in newborns admitted with prematurity. Professional Med J 2021; 28(8):11781182. https://doi.org/10.29309/TPMJ/2021.28.08.6126

\section{INTRODUCTION}

Congenital heart disease (CHD) and Preterm birth are the leading causes of infant mortality and disability of perinatal origin. Preterm babies usually weigh $<2 \mathrm{~kg}$ and constitute around $10 \%$ of all births. ${ }^{1}$ Most of the problems linked with prematurity are observed in babies who weigh less than or equal to $1.5 \mathrm{~kg}$ or babies who are born at $<32$ weeks of gestation. ${ }^{2}$

CHD is one of the commonest birth defects and constitute around $1 / 3^{\text {rd }}$ of all common congenital defects. Prevalence of $\mathrm{CHD}$ range from $5-50 / 1,000$ live births and there is high incidence of CHD in premature neonates, stillbirths or spontaneous miscarriages. ${ }^{3,4} \mathrm{CHD}$ in children contribute significantly towards mortality and it can lead to sudden death later in adult life even if milder heart lesion is present. With the ease of echocardiography of fetus, significant changes have been seen in the occurrence of hemodynamically prominent CHD. Factors which make premature babies more vulnerable during perinatal time are; heat lability, easier to acquire infections, reserved hemodynamic stores, and immature organ systems, especially cardiac muscles, lungs, and liver. And when CHD coexists, it makes whole scenario more complicated. For e.g. the pulmonary vessels in premature babies are said to be less muscularized than in term neonates. This can cause congestive cardiac failure in premature neonates due to left to right shunt defects like ventricular septal defect (VSD) within a few days or weeks after birth. ${ }^{5}$

In a study on incidence of congenital heart disease done at Department of Pediatrics, The Catholic University of Korea School of Medicine, Seoul, Korea, in 2012 showed incidence of CHD 6.8\% in Premature infants. ${ }^{6}$ In another study conducted 
in Paris, France by EPICARD Study Group in 2012 showed that a higher risk of Preterm birth in babies with $\mathrm{CHD}{ }^{7}$

The rationale of the study is to develop guidelines for early screening by echocardiography of premature babies, early referral to specialized centers for early corrective surgery to decrease morbidity, mortality and parents counselling in lesions with poor prognosis. So, we aimed this study to determine the frequency of congenital heart diseases in newborns admitted with prematurity at Children Hospital \& the Institute of Child Health Multan.

\section{MATERIAL \& METHODS}

This descriptive cross sectional study was done at The Department of pediatric Neonatology Children's Hospital \& the Institute of Child Health, Multan, from August 2019 to January 2020.

Sample size was calculated as $P=$ Expected prevalence $=6.8 \%^{6}$, confidence level $=1-\mathrm{a}=$ $95 \%=1.96$, absolute precision required $=d=$ $0.04(4 \%)$, the required sample was 153.

Using non-Probability consecutive sampling technique, all premature newborns of either gender, age less than 28 days were enrolled. Syndromic babies e.g. Down syndrome (Assessed by clinical examination), normal variation of valvular anatomy e.g. isolated bicuspid aortic valve (Assessed by Echocardiography) or isolated dextrocardia (apex of heart on right side) with no other cardiac lesion (Assessed by chest $x$-ray and Echocardiography) were excluded. Study was conducted after taking permission from the institutional ethical committee.

Those patients, who fulfilled the inclusion criteria, were recruited for the study. After explaining all the risks and advantages of the study, written informed consent was obtained from the parents.

Prematurity was defined as a neonate born before 37 completed weeks of estimated gestational age assessed clinically by history and Ballard Scoring (chart attached, score of $\leq 30$ was taken as prematurity). CHD was labeled as structural heart defects i.e. ASD, VSD, PDA, TOF, TGA confirmed on echocardiography with evidence of color and color wave Doppler. Length was measured in centimeters by infantometer. Weight was measured in kilograms by infant weight scale. In preterm newborns of either gender, echocardiography was done by hospital Pediatric Cardiologist (minimum 8 years postgraduate experience) with Echocardiography machine (Toshiba 2 D Nemo XG).

Patient's name, age, gestational age, weight, sex, date, serial number, registration number and echocardiographic results were entered in pre-designed performa. The outcome variable that was frequency of congenital heart disease in preterm newborns was noted.

Data was entered in SPSS (Statistical Package for social science) version 20.0. Descriptive statistics were applied to analyze the data. The quantitative variables i.e. age, gestational age, length and weight were presented as mean and standard deviation. The outcome variables i.e. frequency of congenital heart disease and gender were presented in frequencies and percentages. Confounding factors like age, gestational age and gender were controlled by stratification and Chi-square test was applied to see the effects of these on outcome variables. $\mathrm{P} \leq 0.05$ was taken as significant.

\section{RESULTS}

A total of 155 preterm infants of $\leq 36$ weeks gestational age was included in the study. Median age of the neonates at the time of enrollment into study was 2 days with minimum 1 and maximum 7 days. Median gestational age on delivery was 35 weeks. Minimum gestational age of the included infants was 28 weeks and maximum 36 weeks. Male infants constituted $69 \%(n=107)$ of the infants and females were $31 \%(n=48)$. The average weight of the participants was $1.93 \pm$ $0.37(\mathrm{~kg})$ and the average length was $42.6 \pm 3.75$. (cms) Congenital heart disease was detected in $34.8 \%(n=54)$ preterm infants (Table-I). 


\begin{tabular}{|c|c|c|}
\hline Age (days), median, range & \multicolumn{2}{|c|}{$2,1-7$} \\
\hline $\begin{array}{l}\text { Gestational age (weeks) } \\
\text { Median, range }\end{array}$ & \multicolumn{2}{|c|}{$\begin{array}{c}35 \\
28-36\end{array}$} \\
\hline $\begin{array}{l}\text { Gender } \\
\text { Male } \\
\text { Female }\end{array}$ & $\begin{array}{c}n \\
107 \\
48\end{array}$ & $\begin{array}{c}\% \\
(69) \\
(31)\end{array}$ \\
\hline $\begin{array}{l}\text { Weight }(\mathbf{k g}) \\
\text { Mean } \pm S D\end{array}$ & \multicolumn{2}{|c|}{$1.93 \pm 0.37$} \\
\hline $\begin{array}{l}\text { Length }(\mathbf{c m}) \\
\text { Mean } \pm S D\end{array}$ & \multicolumn{2}{|c|}{$42.6 \pm 3.75$} \\
\hline $\begin{array}{l}\text { Congenital heart disease } \\
\text { Yes } \\
\text { No }\end{array}$ & $\begin{array}{l}\mathbf{n}, \\
54 \\
101\end{array}$ & $\begin{array}{c}\% \\
(34.8) \\
(65.2)\end{array}$ \\
\hline
\end{tabular}

There were $17(11.0 \%)$ infants up to 32 weeks gestation and 138 (89\%) infants 33 - 36 weeks gestation. When categorized on weight $9 \%$ $(n=14)$ were $<1.5 \mathrm{~kg}, 45.2 \%(n=70)$ between $1.5-2.0 \mathrm{~kg}$ and $45.8 \%(n=71)$ were $>2.0 \mathrm{~kg}$ in weight.

Out of 54 preterm infants with congenital heart disease, the commonest lesion was Ventricular Septal Defect (VSD) in 19 (35\%) infants. Second most common lesion detected was Patent ductus arteriosus (PDA) in 15 (28\%) infants. Tetralogy of Fallot (TOF) and Transposition of Great Arteries (TGA) were found in 7 (13\%) infants each. Lowest detected lesion was Atrial Septal Defect (ASD) in $6(11 \%)$ preterm infants (Figure-1).

Table-Il shows that frequency of congenital heart disease was not significantly different ( $p$-value 0.41 ) between male and female preterm infants. Frequency of congenital heart disease was significantly higher ( $p$-value $<0.001$ ) in babies delivered at $\leq 32$ weeks of gestation compared to 33 - 36 weeks of gestation. Frequency of congenital heart disease was significantly higher ( $p$-value $<0.001)$ in infants with weight $<1.5 \mathrm{~kg}$ compared to weight of $1.5-2.0 \mathrm{~kg} \mathrm{\&}>2.0 \mathrm{~kg}$.

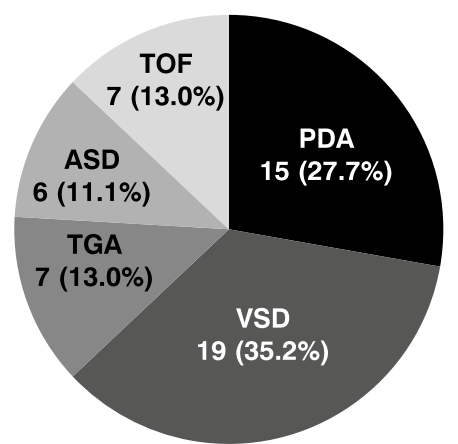

Figure-1. Types of congenital heart diseases in preterm infants $(n=54)$.

\section{DISCUSSION}

Median age of the neonates at the time of enrollment into study, was 2 days. Median gestational age on delivery was 35 weeks. Male infants constituted $69 \%(n=107)$ of the infants and females were $31 \%(n=48)$. The average weight (in $\mathrm{kg}$ ) of the participants was $1.93 \pm 0.37$. Congenital heart disease was detected in $34.8 \%$ $(n=54)$ preterm infants.

In a similar study by Brown $\mathrm{R}$ et al, median gestation age of preterm babies was $32+5$ weeks. The median birth weight was $1.7 \mathrm{~kg} .{ }^{8} \mathrm{In}$ another study by Dees $\mathrm{E}$ et al, the median gestational age was 33 weeks, while the mean birth weight of the preterm neonates was $1.8 \mathrm{~kg} .^{5}$

\begin{tabular}{|l|c|c|c|}
\hline \multicolumn{2}{|c|}{ Characteristics } & \multicolumn{2}{c|}{ Congenital Heart Disease } \\
\cline { 2 - 4 } & & No (n=101) & Yes (n=54) \\
\hline \multirow{2}{*}{ Gender } & Male & $72(71.3 \%)$ & $35(64.8 \%)$ \\
\hline \multirow{2}{*}{ Gestational Age } & Female & $29(28.7 \%)$ & $19(35.2 \%)$ \\
\hline \multirow{3}{*}{ Birth Weight } & Up to 32 weeks & $03(3.0 \%)$ & $14(82 \%)$ \\
\hline & $33-36$ weeks & $98(97.0 \%)$ & $40(28 \%)$ \\
\hline
\end{tabular}

Table-II. Association of Congenital heart disease frequency with gender, Gestational Age and Birth Weight among preterm Infants $(\mathbf{N}=155)$. 
In a study by Cho SY et al, congenital heart disease was observed in $6.8 \%$ of preterm infants. ${ }^{6}$

Laas $\mathrm{E}$ et al found association between preterm birth and CHD. They observed that, of all the newborns with CHD included in the study, $13.5 \%$ were preterm. ${ }^{1}$

Our study showed that out of 54 preterm infants with congenital heart disease, the commonest lesion was Ventricular Septal Defect (VSD) in 19 (35\%) infants followed by Patent ductus arteriosus (PDA) in 15 (28\%) infants. Tetralogy of Fallot (TOF) and Transposition of Great Arteries (TGA) were found in 7 (13\%) infants each. Lowest detected lesion was Atrial Septal Defect (ASD) in $6(11 \%)$ preterm infants. In a study conducted by Cho SY et al, types of CHD identified in neonates were as follows: ASD $(n=93,41 \%)$, VSD $(n=72$, $32 \%)$, and PS $(n=33,15 \%) .{ }^{6}$ This is in contrast to our study where ASD was detected in only $11 \%$ preterm babies. Our results are more aligned with local findings by Zahid SB et al where they noted VSD to be the commonest lesion among children with $\mathrm{CHD} .{ }^{9}$ Globally, VSD is considered to be most abundant form of CHD accounting for $25-30 \%$ of $\mathrm{CHD}$ cases. ${ }^{10}$

Frequency of congenital heart disease was significantly higher ( $p$-value < 0.001) in infants born at $\leq 32$ weeks of gestation compared to 33 - 36 weeks of gestation. Also, frequency of congenital heart disease was significantly higher ( $p$-value $<0.001)$ in infants with weight $<1.5$ $\mathrm{kg}$ compared to weight of $1.5-2.0 \mathrm{~kg} \&>2.0$ kg. In 2010, Godfrey M et al conducted a study on relationship of congenital heart disease and birth weight and observed that out of 437 low birth weight infants, 19 (4.4\%) had CHD. In the subcategory of 154 babies with birth weight $<1 \mathrm{~kg}$, $10(6.6 \%)$ patients had CHD. In the category of 283 babies with birth weight $1-1.5 \mathrm{~kg}, 9$ (3.2\%) patients had CHD. ${ }^{11}$ Elshazali $\mathrm{HOH}$ et al also observed similar association in their study where out of 141 newborns, $31.9 \%$ were born with low or very low birthweight. ${ }^{12}$

Researchers from other parts of the world have attributed very preterm or low birth- weight to be associated with higher rates of CHDs among newborns. ${ }^{13-15}$ There is a need to create awareness in childcare health facilities about proper screening and care for premature newborns regarding increased risk of $\mathrm{CHD}$.

\section{CONCLUSION}

Our study highlights the association of CHD in premature and low birth weight neonates. So, every preterm and low birth weight neonate must undergo echocardiography to screen for CHD so that earlier diagnosis may be made for earlier intervention. While in majority cases, minor CHDs do not require special intervention and certainly many of these defects, for e.g. the small VSD, ASD or PDA, can later on close spontaneously or sometimes do not produce significant symptoms.

Copyright(C) 19 Dec, 2020.

\section{REFERENCES}

1. Laas E, Lelong N, Thieulin AC, Houyel L, Bonnet D, Ancel PY, et al. Preterm birth and congenital heart defects: A population-based study. Pediatrics. 2012; 130(4):e829-37.

2. Trachtenbarg DE, Golemon TB. Care of the premature infant: Part I. Monitoring growth and development. Am Fam Physician. 1998; 57(9):2123-30.

3. Khalil A, Aggarwal R, Thirupuram S, Arora R. Incidence of congenital heart disease among hospital live births in India. Indian Pediatr. 1994; 31(5):519-27.

4. Anderson AW, Smith PB, Corey KM, Hill KD, Zimmerman $\mathrm{KO}$, Clark $\mathrm{RH}$, et al. Clinical outcomes in very low birth weight infants with major congenital heart defects. Early Hum Dev. 2014; 90(12):791-5.

5. Dees E, Lin H, Cotton RB, Graham TP, Dodd DA. Outcome of preterm infants with congenital heart disease. J Pediatr. 2000; 137(5):653-9.

6. Cho SY, Oh JH, Lee JH, Lee JY, Lee SJ, Han JW, et al. Recent incidence of congenital heart disease in neonatal care unit of secondary medical center: A single center study. Korean J Pediatr. 2012; 55(7):2327 .

7. Laas E, Lelong N, Ancel PY, Bonnet D, Houyel L, Magny JF, et al. Impact of preterm birth on infant mortality for newborns with congenital heart defects: The EPICARD population-based cohort study. BMC Pediatr. 2017; 17(1):124. 
8. Brown R, Wren K, Singh Y. G406 Congenital heart defects in preterm infants. Arch Dis Child. 2017; 102:A159-A160.

9. Bakhtyar Zahid S, Zeb Jan A, Ahmed S, Achakzai H. Spectrum of congenital heart disease in children admitted for cardiac surgery at Rehman Medical Institute, Peshawar, Pakistan. Pak J Med Sci. 2013; 29(1):173-176.

10. Godfrey M, Schimmel MS, Hammerman C, Farber B. The incidence of congenital heart defects in very low birth weight and extremely low birth weight infants. Isr Med Assoc J. 2010; 12(1):36-8.

11. Richard EBehrman, Robert $M$, Kliegman \& HalB. Nelson Text Book of Pediatrics. 17th ed. 2004. pp. 1499-1502.
12. Elshazali $\mathrm{HOH}$, Elshazali $\mathrm{OH}$, Elshazali $\mathrm{H}$. The relationship between birth weight and congenital heart disease at Ahmed Gasim Cardiac Centre, Bahri, Sudan. Sudan J Paediatr. 2017; 17(2):49-55.

13. Polito A, Piga S, Cogo PE, Corchia C, Carnielli V, Da Frè $M$, et al. Increased morbidity and mortality in very preterm/VLBW infants with congenital heart disease. Intensive Care Med. 2013; 39:1104-12.

14. Lin HJ, Du LZ, Ma XL, Shi LP, Pan JH, Tong XM, et al. Mortality and morbidity of extremely low birth weight infants in the Mainland of China: A multi-center study. Chin Med J. 2015; 128:2743-50.

15. Chu PY, Li JS, Kosinski AS, Hornik CP, Hill KD. Congenital heart disease in premature infants 25-32 weeks' gestational age. J Pediatr. 2017; 181:37-41.

\section{AUTHORSHIP AND CONTRIBUTION DECLARATION}

\begin{tabular}{|c|l|l|l|}
\hline Sr. \# & \multicolumn{1}{|c|}{ Author(s) Full Name } & \multicolumn{1}{|c|}{ Contribution to the paper } & Author(s) Signature \\
\hline 1 & Sana llyas & $\begin{array}{l}\text { Data Collection, Data } \\
\text { Analysis, Drafting. } \\
\text { Methodology, Literature } \\
\text { review. }\end{array}$ \\
\hline 3 & Sana Waqar & $\begin{array}{l}\text { Study concept, Proof } \\
\text { reading, Supervision. } \\
\text { Data collection, Literature } \\
\text { review. }\end{array}$ \\
\hline
\end{tabular}

